\title{
Hasarlı Kurşun Koruyucu Giysilerin Atık Kriterlerinin Belirlenmesi
}

\author{
Ayşegül Yurt ${ }^{1,2 *}$, Mustafa Tintaş ${ }^{1,3}$ \\ ${ }^{1}$ Dokuz Eylül Üniversitesi, Sağlık Bilimleri Enstitüsü, Medikal Fizik AD, İzmir, Türkiye (ORCID 0000-0001-6512-4950) \\ ${ }^{2}$ Dokuz Eylül Üniversitesi, Sağlık Hizmetleri Meslek Yüksekokulu, İZMIR, Türkiye (ORCID 0000-0001-6512-4950) \\ ${ }^{3}$ Sakarya Üniversitesi, Araştırma ve Uygulama Hastanesi, Radyasyon Onkolojisi AD, Sakarya, Türkiye (ORCID 0000-0002-1477-7959)
}

(Illk Geliş Tarihi 21 Şubat 2019 ve Kabul Tarihi 15 Mayıs 2019)

(DOI: $10.31590 /$ ejosat.530063)

ATIF/REFERENCE: Yurt, A. \& Tintaş, M. (2019). Hasarlı Kurşun Koruyucu Giysilerin Atık Kriterlerinin Belirlenmesi. Avrupa Bilim ve Teknoloji Dergisi, (16), 395-402.

\section{$\ddot{\mathrm{O} z}$}

Amaç: Radyasyondan korunmada, kişisel korunma için kurşun koruyucu giysiler sıklıkla kullanılmaktadır. Bu koruyucular, kullanım ve depolama şartları gibi nedenlerle zamanla hasar görebilmektedir. Bundan dolayı kurşun koruyucu giysilerin yılda bir kez kalite kontrollerinin yapılarak hasarlı ve riskli olanların belirlenmesi, radyasyon çalışanlarının kişisel korunmasında büyük önem taşımaktadır. Bu çalışmanın amacı, radyasyonla çalışan birimlerde kullanılan hasarlı kurşun koruyucu giysileri ve onlar için atık kriterlerini belirlemektir.

Materyal ve Yöntem: Bu çalışmada, hastanemizde kullanılan 167 kurşun koruyucu giysinin floroskopi eşliğinde yapılan kalite kontrol çalışmasında; delik/yırtık sayıları, bu deliklerin toplam alanları, x ışıllarını \% geçirme oranları ve delik/yırtık altındaki eşdeğer ve ek doz değerleri belirlendi. Elde edilen bu verilerle, hasarlı ve riskli kurşun koruyucu giysiler belirlendi ve hasarlı kurşun giysiler için literatür destekli atık kriterleri tanımlandı.

Bulgular: Literatüre göre atık kriterleri, delik/yırtık alanının $10 \mathrm{~cm}^{2}$ ve fazlası, yüzde geçirme miktarının $\% 5$ ve fazlası, etkin doz değeri ise $0,4 \mathrm{mSv}$ olarak belirlendi. Bu atık kriterleriyle yapılmış olan hasar değerlendirme kalite kontrol çalışmasına göre kurşun koruyucuların $\% 7,8^{\prime} \mathrm{i}$ atık ve $\% 12,8^{\prime} \mathrm{i}$ ise riskli olarak tespit edildi.

Sonuç: Kurşun koruyucu giysiler için hem kişisel radyasyondan korunmadaki güvenlik hem de maliyetleri açısından bu kriterlere göre hasarlı ve atık kararının verilmesi önemlidir. Hasarlı kurşun koruyucu giysilerin atık kriterlerine bağlı olarak kullanımdan çıkarılması, gereksiz kurşun önlük atı̆̆ının olmasını da önler.

Anahtar sözcükler: Atık kriterleri, İş güvenliği, Radyasyon koruyucuları, Radyasyon dozu, Radyasyondan korunma

\section{Determination of Rejecting Criteria in Lead Protective Apparels}

\begin{abstract}
Introduction: Lead protective apparels such as lead aprons, thyroid shields, and gonadal shielding are being used frequently for personal protection from radiation. These lead protectives may also be damaged frequently because of the usage and storage conditions. Therefore, the quality control of lead protective apparels which are performed once a year and the determination of damaged and risky ones are of great importance in the personal protection of radiation workers. In this study, it was aimed to determine the reject criteria by identifying damaged lead protective apparels.

Material and Method: In this study, the numbers of tears, the total area of these tears, \% shielding effect of x-rays and effective dose values were determined by the quality control inspection with the assistance of fluoroscopy of 167 lead protectives which were used in our hospital. Based on the data obtained, damaged and risky lead protectives were determined. In addition to this, the criteria rejection of the damaged lead clothing according to the literature have been defined for the protection radiation purposes.
\end{abstract}

\footnotetext{
* Ayşegül Yurt: Dokuz Eylül Üniversitesi, Sağl1k Bilimleri Enstitüsü, Medikal Fizik AD., İzmir, Türkiye, ORCID: 0000-0001-6512-4950, aysegul.yurt@deu.edu.tr
} 
Results: According to the literature, the rejection criteria were determined as $10 \mathrm{~cm} 2$ and higher of the hole/tear area, for percent transmission value $\% 5$ and higher, and the effective dose value of $0,4 \mathrm{mSv}$. According to the damage assessment quality control study performed with these waste criteria, $7,8 \%$ of the lead shields were determined as waste and 12,8\% as risky.

Conclusion: Criteria have been set for the damaging decision of the lead protective apparels which have high cost and radiation protection. Removal of damaged lead protective clothes depending on waste criteria, it also prevents unnecessary lead apron waste.

Keywords: Reject criteria, Occupational safety, Radiation dose, Radiation protection, Radiation protective

\section{Giriş}

Günümüz tıp teknolojisinde hastalıkların erken ve doğru teşhisinde radyolojik görüntülemenin önemi büyüktür. Bu amaçla hastanelerin ve görüntüleme merkezlerinin radyoloji bölümlerinde anjiyografi, floroskopi, konvansiyonel görüntüleme, seyyar röntgen, dental görüntüleme, bilgisayarlı tomografi gibi birçok farklı cihazlarda X-1şınları gibi iyonlaştırıcı radyasyon kullanımına sıkça rastlanmaktadır (Jones ve Wagner, 2013; Lambert ve McKeon, 2001). Radyasyondan korunmanın temel ilkelerinden biri olan ALARA(As Low As Reasonably Achievable)'ya göre; optimum görüntü kalitesi, en az radyasyon dozu ile elde edilmelidir. Ancak maruz kalınan doz, bazı girişimsel uygulamalarda uluslararası otoriteler tarafından izin verilen doz sınırlarının üzerine çıkabilmektedir. Çünkü konvansiyonel radyografiye göre girişimsel radyografi gibi çalışmalarda uygulamanın tipi ve süresine bağlı olarak toplam doz da her geçen gün daha fazla artmaktadır (Stam ve Pilay, 2008). Bundan dolayı, radyasyonun zararlı etkileri nedeniyle uygulama sırasında hastanın ve uygulamayı yapan personelin, radyasyondan korunması şarttır. Kurşunun, radyasyon soğurma yeteneğinin yüksek olması ve geniş bir enerji aralığında etkin bir koruma sağlaması nedeniyle kurşun içerikli koruyucu giysiler radyasyon korunmasında oldukça sık kullanılmaktadır (Oyar ve Kışlalıoğlu, 2012). Öte yandan kurşunun ucuz ve kolay işlenebilen bir element olması, ikinci bir tercih sebebidir. Radyasyonun tipine ve enerjisine bağlı olarak farklı kalınlıkta $(0,25 \mathrm{mmPb}, 0,35 \mathrm{mmPb}$ ve $0,50 \mathrm{mmPb})$ kurşun koruyucular (kurşun önlük, troid koruyucu, gonad koruyucu vb. giysiler) kullanılmaktadır (Çetin vd., 2016).

Kurşun, alaşım olduğundan dolayı uygun şartlarda kullanılmadığında kırılma ve çatlaklar olabilmektedir. Bu hasarlar, kurşun koruyucunun yaşı ya da kullanım hatalarından kaynaklanmaktadır (Stam ve Pilay, 2008). Bu nedenle kurşun koruyucu önlüklerin rutin kontrolü yapılmazsa zamanla oluşabilecek delik/yırtıklar nedeniyle onu giyen kişinin alacağı radyasyon dozu da önemli ölçüde artabilecektir. $\mathrm{Bu}$ nedenle kurşun önlük, troid koruyucu, gonad koruyucu gibi kurşun koruyucu giysilerin yıllık kalite kontrolleri yapılarak delik/yırtığın boyutunun ve konumunun belirlenmesi, gerektiğinde bu önlüğün atılarak yerine yenisinin alınmasına gerek olup olmadığına karar vermede büyük öneme sahiptir (Stam ve Pilay, 2008). Hastanelerde koruyucu kurşun giysilerin kalite kontrol çalışması yapılarak, bunların tam hasarlı, yarı hasarlı ve hasarı olmayanlar olarak sınıflandırıldıktan sonra risk değerlendirmesi yapılarak atılacakların belirlenmesi gerekmektedir.

Bu çalışmada, hastanemizdeki kurşun koruyucu giysilerin kalite kontrol çalışması yapılarak hasarlı olanlar belirlendi ve delik/yırtık alanı, birincil ve ikincil radyasyonu \% geçirme değerleri, etkin doz değerleri arasındaki ilişki incelenerek atık kriterlerinin ortaya konulması amaçlandı. Bu atık kriterleri, hastaneler ve ilgili kurumlarda kullanılan kurşun koruyucu giysilerin kalite kontrolleri sonrasında atık kararının verilmesinde önemli rol oynayacaktır.

\section{Materyal ve Metot}

Hastanemizde 6 farklı bölümde (Nükleer Tıp Bölümü, Radyoloji Bölümü, Gündüz Tedavi Merkezi, Kardiyoloji Bölümü (Anjiyo Birimi), Acil Servis, Ameliyathane Birimi) kullanılmakta olan 0,25 mmPb ve 0,5 mmPb kalınlığındaki 167 kurşun koruyucu giysinin kalite kontrolü, floroskopi cihazı ile yapıldı. Bu kurşun koruyucu giysilerin 120'si kurşun önlük, 38'i tiroid koruyucu ve 9'u gonad koruyucuydu. Kurşun koruyucu giysilerin hangi bölümlere ait olduğunu belirtmek amacıyla önce kodlama işlemi yapıldı. Daha sonra her bir kurşun giysinin özellikleri (marka, kurşun eşdeğerliği, seri no vb.) kaydedildi. Kurşun koruyucu giysiler floroskopi eşliğinde 100 kVp'de taranarak, hasarlı olanlar tespit edildikten sonra hasarlı olanların delik/yırtık olan kısımlarının radyografik görüntüleri alındı ve PACS'da (Picture and Archiving Communication System, PHILIPS iSite Radiology, version 4.1.110) saklandı. Elde edilen bu görüntülerdeki delik/yırtık alanlarının hesaplamasında sisteminin yazılım programından yararlanıldı (Şekil 1). 


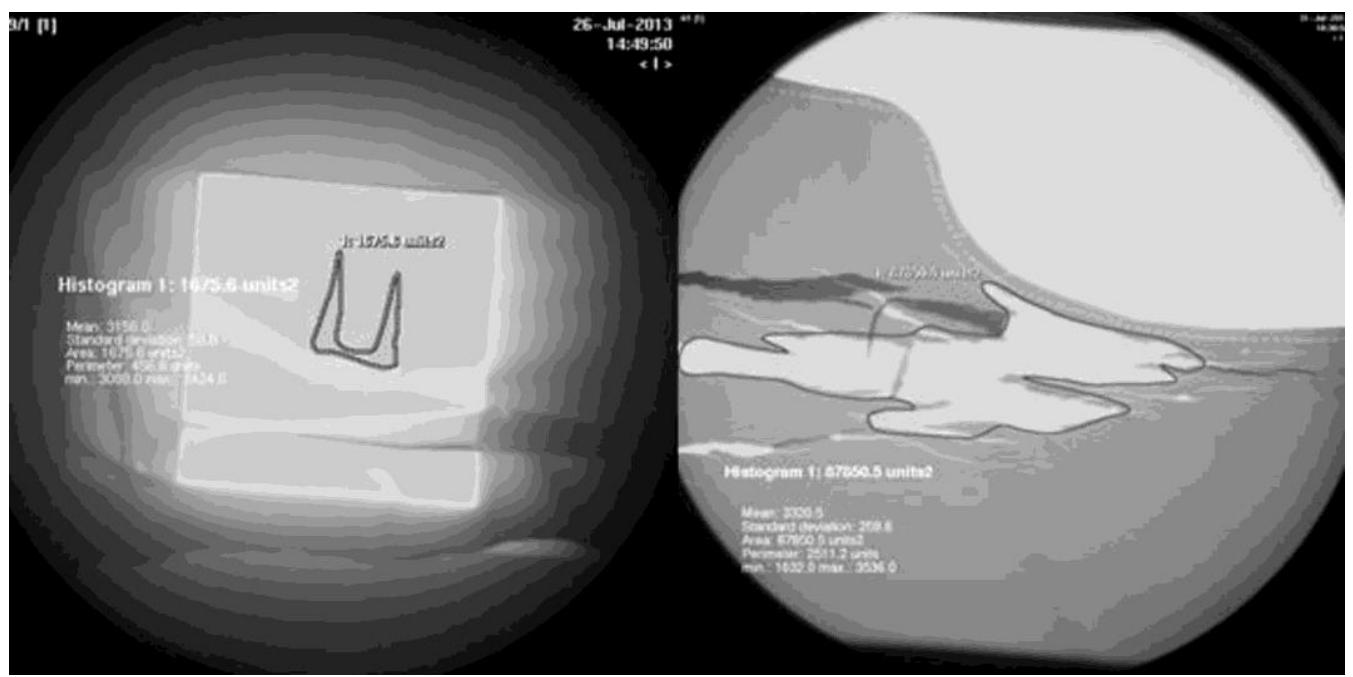

Şekil 1: Floroskopi eşliğinde kalite kontrolleri yapılan kurşun önlüklerde belirlenen delik/yırtıklar ve bunlara ait alan ölçümü

Delik/yırtık alanlar belirlendikten sonra bu hasarlı alanların radyasyonu ne kadar geçirdiğini belirleyebilmek için Şekil 2'deki düzenek kullanıldı. Şekil 2a'da, hiçbir engel olmadan tüp çıkışı radyasyon doz değerleri, bir iyon odası (PTW marka, $6 \mathrm{~cm}^{3}$ hassasiyetli hacimli ve 50-150kV aralığında) kullanılarak belirlendi. Şekil 2b'de ise iyon odası üzerine delik/yırtık olan kurşun koruyucu giysi konularak bu koruyucunun radyasyonu ne kadar geçirdiği belirlendi. Yani, birincil ölçümlerde ilk önce havadaki doz belirlendikten sonra kurşun koruyucu giysi altına iyon odası konularak aynı değerlerde ışınlama tekrarlanmak suretiyle kurşun giysinin azaltma değerleri belirlendi. İkincil (saçılan) radyasyon doz değerlendirmesinde de $50 \mathrm{~cm}$ kalınlığındaki PMMA (Polymethyl methacrylate) fantom masaya konulup, masadan $50 \mathrm{~cm}$ uzaklığa kurşun koruyucu giysi bir askıyla yerleştirildi (Şekil 3a ve Şekil 3b). Geiger Müller dedektörü (GM dedektör) yardımıyla tüm vücut koruyucu giysileri için kurşun koruyucuların önü ve arkasında ölçümler alındı.
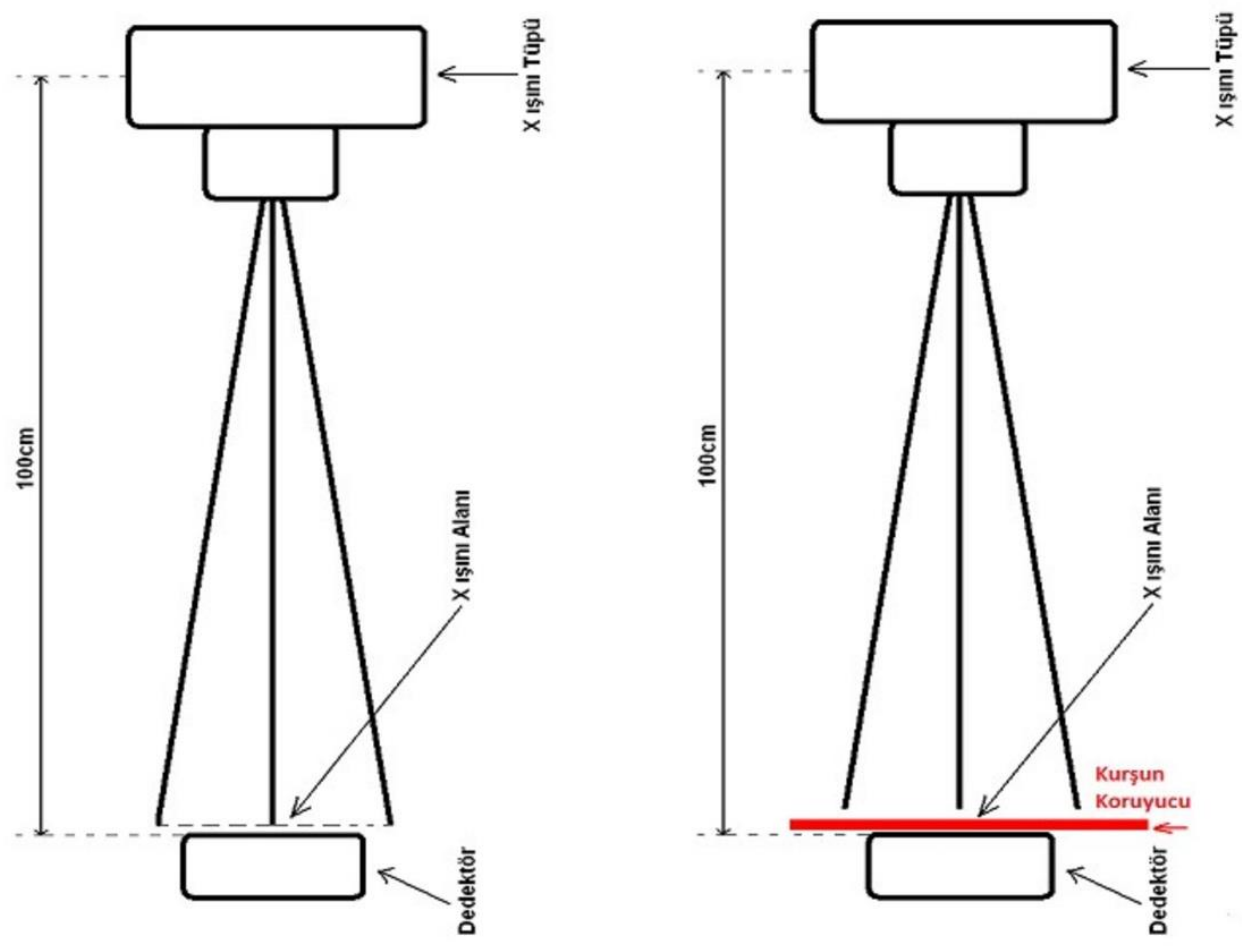

Şekil 2: (a) Birincil x-ışınlarının havadaki doz değerlerinin belirlenmesindeki ölçüm düzeneği (b) Kurşun koruyucudaki yırtık altı birincil radyasyon değerlerinin belirlenmesindeki ölçüm düzeneği 

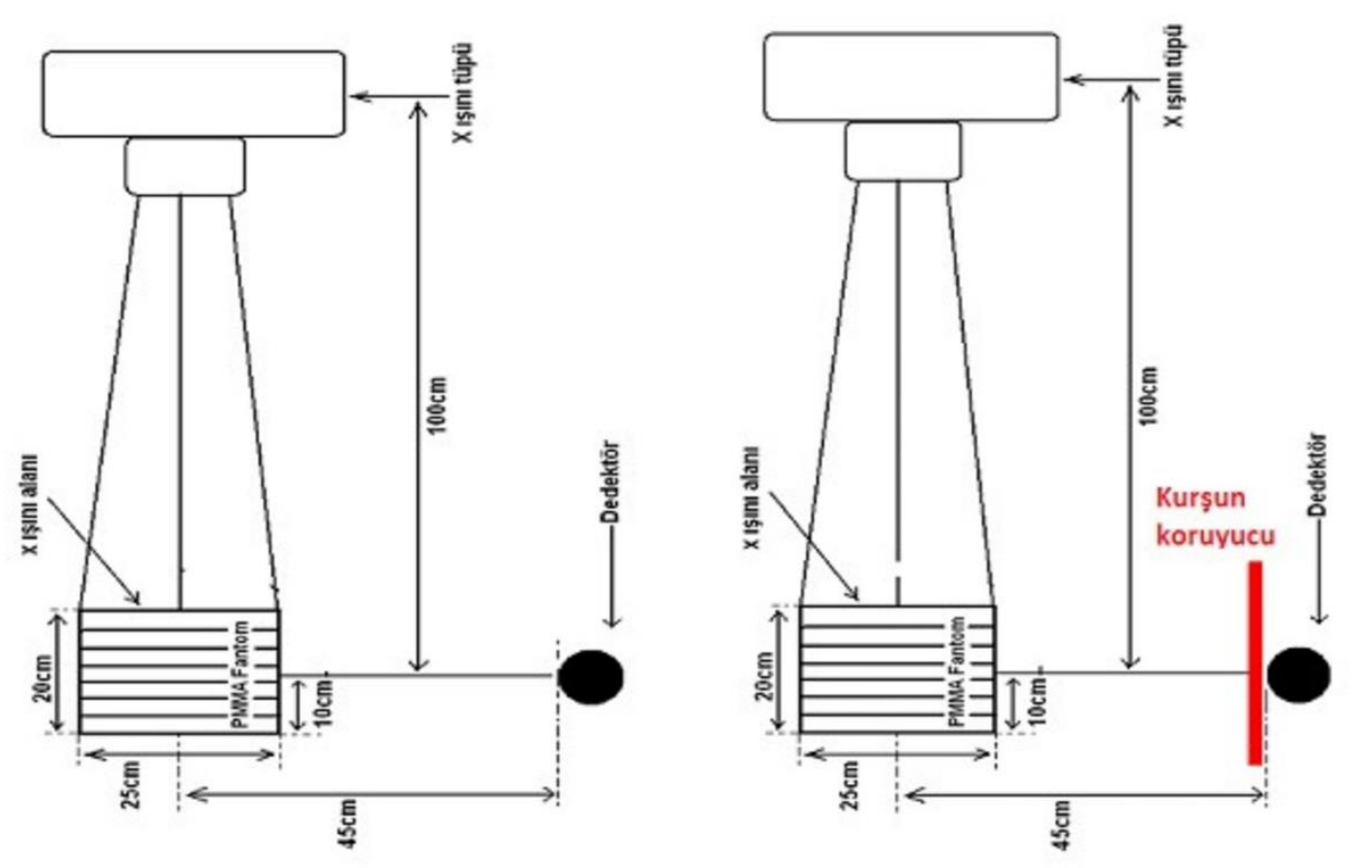

Şekil 3: (a) Saçılan x-ışınının havadaki doz değerlerinin ölçüm düzeneği (b) Saçılan x-ışını kurşun koruyucu altındaki doz değerlerinin ölçüm düzeneği

Her bir kurşun koruyucu giyside kaç tane delik/yırtık olduğu belirlendikten sonra kurşun giysilerin belirlenen alanları altında birincil ve saçılan (ikincil) radyasyon değerleri ölçüldü ve radyasyonu geçirme oranları eşitlik 1 ile hesaplandı (Zuguchi vd., 2008; Çetin vd., 2016).

$\%$ Soğurma etkisi $=\frac{\text { Havadaki doz ölçümü-kurşun önlük altındaki doz ölçümü }}{\text { Havadaki doz ölçümü }} \times 100$

Havadaki doz ölçümü, kurşun önlük olmadan alınan radyasyon ölçüm değeri olmak üzere x ışınlarının kurşun koruyucu giysilerden \% geçiş oranları belirlendi.

Kurşun koruyucu giysilerdeki bir delik/yırtıktan dolayı belirli bir limit dozun aşılması ve belli bir geçiş değerinin beklenilen değerin üstünde olması durumunda alınan dozun belirlenmesi büyük önem taşımaktadır. Bu nedenle bir kurşun önlükte, a alanına sahip delik/yırtığın toplam etkin dozu hesaplamak için Eşitlik 2 kullanıldı (Lambert ve Mckeon, 2001;S tam ve Pilay, 2008).

$$
E_{\text {top }}(a)=w_{t} \times D \times T \times\left(1-\frac{a}{A}\right)+w_{t} \times D \times\left(\frac{a}{A}\right)
$$

$\mathrm{W}_{\mathrm{t}}$ : tüm vücut için doku ağırlık faktörü

$\mathrm{D}(\mathrm{mGy})$ : kurşun önlük tarafından azaltılan doz

T: kurşun önlükten geçirim faktörü

a $\left(\mathrm{cm}^{2}\right)$ : yırtığın alanı

A, ilgilenilen kurşun koruyucunun bölge veya yüzey alanı

100 kV'de değerlendirme yapıldığından dolayı bu hesaplamalarda ICRP 60 nolu raporuna göre tüm vücut kurşun giysi için $\mathrm{w}_{\mathrm{t}}=1$, $\mathrm{A}=4000 \mathrm{~cm}^{2}, 0,5 \mathrm{mmPb}$ önlükler için kurşun önlük geçirim faktörü $\mathrm{T}=0,038$ (Tablo 1) olarak belirlendi. $\mathrm{D}$, doz azaltım değerleri (Eşitlik 1'den hesaplanan değerler) ve her bir yırtığın alanı a değerleri belirlenerek eşitlik 2'den kurşun koruyucu giysiler için toplam etkin doz hesaplamaları yapıldı (Duran ve Emmy, 2003; Stam ve Pilay, 2008). Elde edilen verilerin istatistiksel değerlendirilmesinde SPSS 20.0 versiyon (Statistical Package for the Social Sciences 20.0 version) kullanıldı. Bu çalışmada çift kat ve $0,25 \mathrm{mmPb}$ önlükler çok az olduğu için istatistik değerlendirmeye alınmadı. 
Tablo 1: Farklı kurşun eşdeğerli önlükler için elde edilen geçirim değerleri (Stam ve Pilay, 2008)

\begin{tabular}{c|c}
\hline $\mathbf{d}(\mathbf{m m P b})$ & Geçirim katsayısı T(-) \\
\hline 0,25 & 0,19 \\
\hline 0,35 & 0,10 \\
\hline 0,50 & 0,038 \\
\hline 0,70 & 0,010 \\
\hline 1,00 & 0,0014 \\
\hline
\end{tabular}

\section{Araştırma Sonuçları ve Tartışma}

Gerçekleştirilen kalite kontrol çalışması sonucunda incelemeye alınan 38 troid ve 9 gonad koruyucuda herhangi bir hasara rastlanmadı. Bununla birlikte incelemeye alınan 120 kurşun önlüğün 78 tanesinde bir ya da birden daha fazla yırtık tespit edildi. Tüm kurşun önlükler arasında hasarlı kurşun önlüklerdeki yırtık sayılarının sıklığı, Tablo 2'de verilmiştir.

Tablo 2: Hasarlı önlüklerdeki delik/yırtık sayılarının önlük sayılarına göre dağıllımı

\begin{tabular}{c|c|c}
\hline Yırtık sayısı & Önlük sayısı & $\begin{array}{c}\text { Hasarlı önlüklere göre \% } \\
\text { oran }\end{array}$ \\
\hline 1 & 20 & 25,6 \\
\hline 2 & 12 & 15,4 \\
\hline 3 & 6 & 7,7 \\
\hline 4 & 20 & 25,6 \\
\hline 5 & 5 & 6,4 \\
\hline 7 & 7 & 9,0 \\
\hline 8 & 8 & 10,3 \\
\hline Toplam & $\mathbf{7 8}$ & $\mathbf{1 0 0 , 0}$ \\
\hline
\end{tabular}

Hasarlı önlüklere bakıldığında 4 ve üzeri delik/yırtık olan önlüklerin toplamının hasarlı önlük sayısının yarısından fazla olduğu gözlemlenmiştir. Birimlere ait hasarlı önlüklerin delik/yırtık sıklığı, toplam alanları, \% geçiş oranları ve etkin doz göre dağılımı Tablo 3'de gösterilmektedir.

Tablo 3: Hasarll önlüklerin yırtık slklığı, toplam alanı, \% geçiş oranı ve etkin doz değerlerine göre dă̆glımı

\begin{tabular}{|c|c|c|c|c|}
\hline Bölüm & Yırtık sıklığı & $\begin{array}{c}\text { Yurtık toplam } \\
\text { alanı }\left(\mathrm{cm}^{2}\right)\end{array}$ & $\begin{array}{c}\% \text { Geçirme } \\
\text { oranı }\end{array}$ & Etkin Doz \\
\hline $2 A 6$ & 4 & 69,00 & 2,8 & 0,27 \\
\hline $1 A 1$ & 7 & 94,1 & 3,1 & 0,51 \\
\hline $1 A 4$ & 8 & 418,7 & 2,6 & 0,65 \\
\hline $1 A 5$ & 4 & 54,5 & 2,7 & 0,13 \\
\hline$A M L 1$ & 7 & 15,01 & 2,5 & 0,13 \\
\hline$A M L 4$ & 8 & 67,7 & 10,3 & 0,21 \\
\hline$A M L 5$ & 3 & 23,5 & 3,1 & 0,19 \\
\hline AML6 & 4 & 99,6 & 3,2 & 0,28 \\
\hline GND2 & 5 & 13,75 & 3,03 & 0,31 \\
\hline ANJ8 & 2 & 98,7 & 3,69 & 0,16 \\
\hline NTP7 & 4 & 24,18 & 0,69 & 0,26 \\
\hline NTP9 & 2 & 32,7 & 0,51 & 0,14 \\
\hline KRD 3 & 1 & 252,3 & 5,01 & 0,16 \\
\hline$K R D 4$ & 1 & 1505,8 & 10,62 & 0,62 \\
\hline$K R D 6$ & 1 & 1586,6 & 9,49 & 0,65 \\
\hline KRD10 & 1 & 252,5 & 10,16 & 0,16 \\
\hline
\end{tabular}


Atık kriterini belirlemek için hasarlı önlüklerden kaynaklı dozun, radyasyon çalışanlarının yıllık alabileceği ortalama yıllık doz değeri olan 20 mSv’ın 1/10'u yani 2 mSv geçmemesi planlanmalıdır. Bu referans değerleri içine alan literatürlerden, hasarlı kurşun önlükler için verilen değerler atık kriterini belirlemede göz önüne alındı. Çalışmamızda belirlenen hasarlı kurşun önlükler için atık kriterleri, literatüre göre \% geçirme oranı için $\% 5$ ve üstü; delik/yırtık alanı için $10 \mathrm{~cm}^{2}$ ve etkin doz değerlendirmesinde ise $400 \$$ 'lık bir kurşun önlük için doz kriteri yaklaşımıyla belirlenen 0,4 mSv olarak belirlendi (Lambert ve McKeon, 2001; Stam ve Pilay, 2008; Duran ve Emmy, 2003). Bu kriterlerden en az 2 tanesini aşanlar, hasarlı önlük olarak belirlendi. Bu kriterlere göre Tablo 3'e bakıldığında, hasarlı önlüklerin büyük bir çoğunluğunun ameliyathane ve kardiyoloji bölümünde kullanılan önlükler olduğu görüldü. Buna göre hasarlı önlük oranı, tüm önlüklerin $\% 7,8$ 'ini oluştururken riskli önlük oranı, \%12,8 olarak bulundu. Şekil 4'de atık kararı alınan önlüklere birkaç örnek gösterilmektedir.

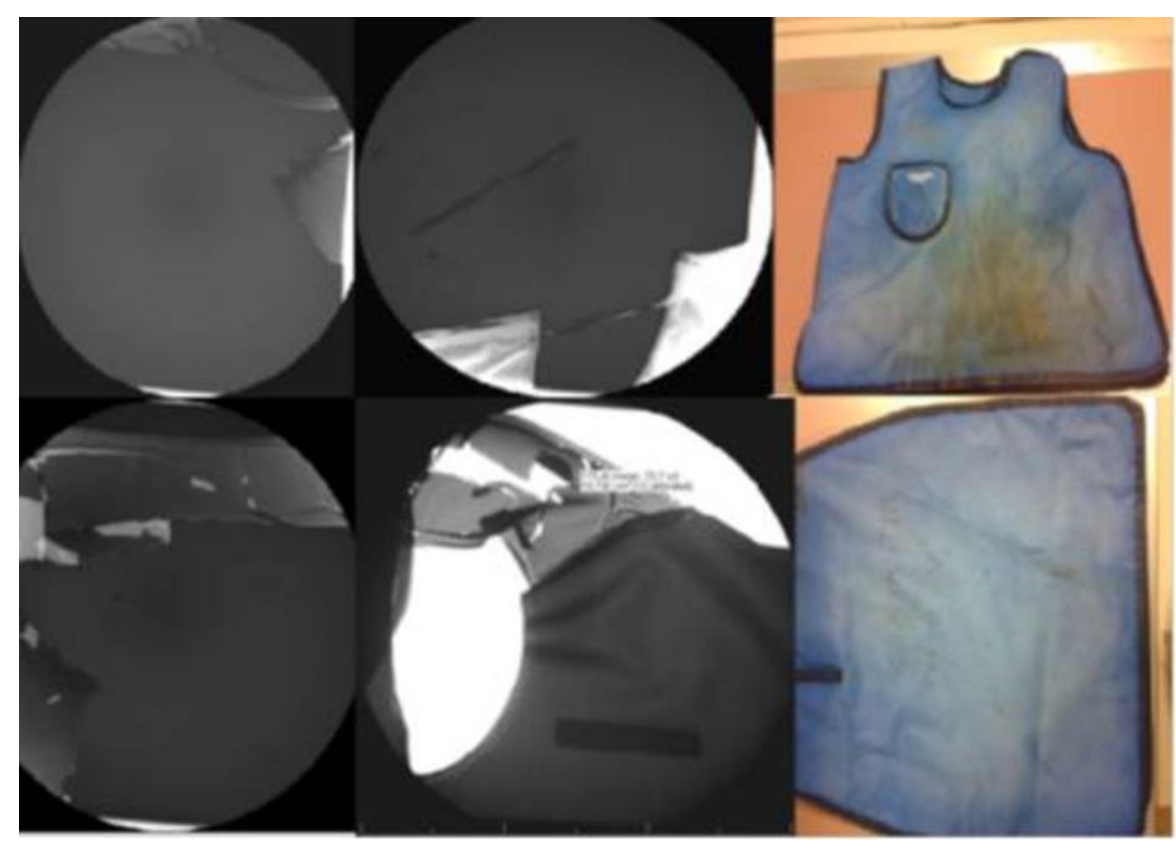

Şekil 4: Atık kararı alınan 7 adet delik/yırtık olan etek-yelek kurşun koruyucu giysi

Hasarlı kurşun önlüğe ait delik/yırtık alanı ile etkin doz değerlerinin grafiği Şekil 5'deki gibidir.

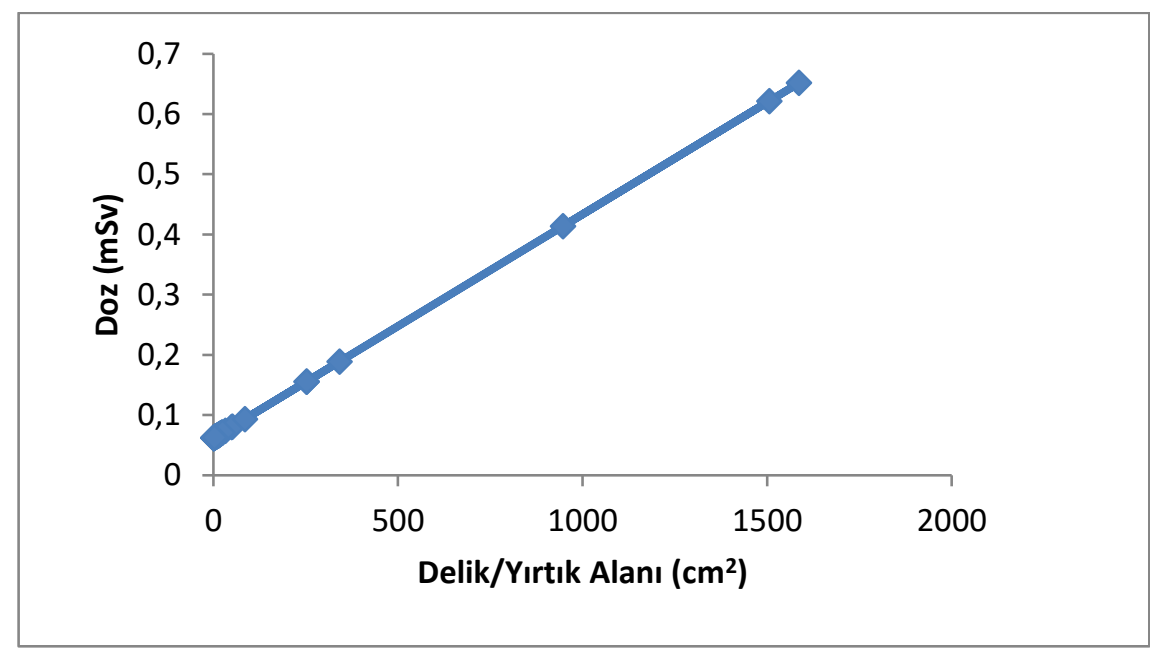

Şekil 5: Delik/yırtık alanının büyüklüğ̈̈ne göre değişen etkin doz değerleri

Şekil 5 'te yırtık alanı arttıkça etkin doz miktarında da lineer bir artışı olduğu görüldü. Bu da alan arttıkça kullanıcıların alacağı radyasyon dozunun artacağı anlamına gelmektedir.

$\mathrm{Bu}$ çalışmanın sonuçlarının doğrulaması ve sonraki yıllarda da kurşun giysilerin kalite kontrolünde kullanılabilmesi için belirlediğimiz delik/yırtık alanına göre etkin doz ölçümleri yapıldı ve kalibrasyon eğrileri çizildi (Şekil 6). 


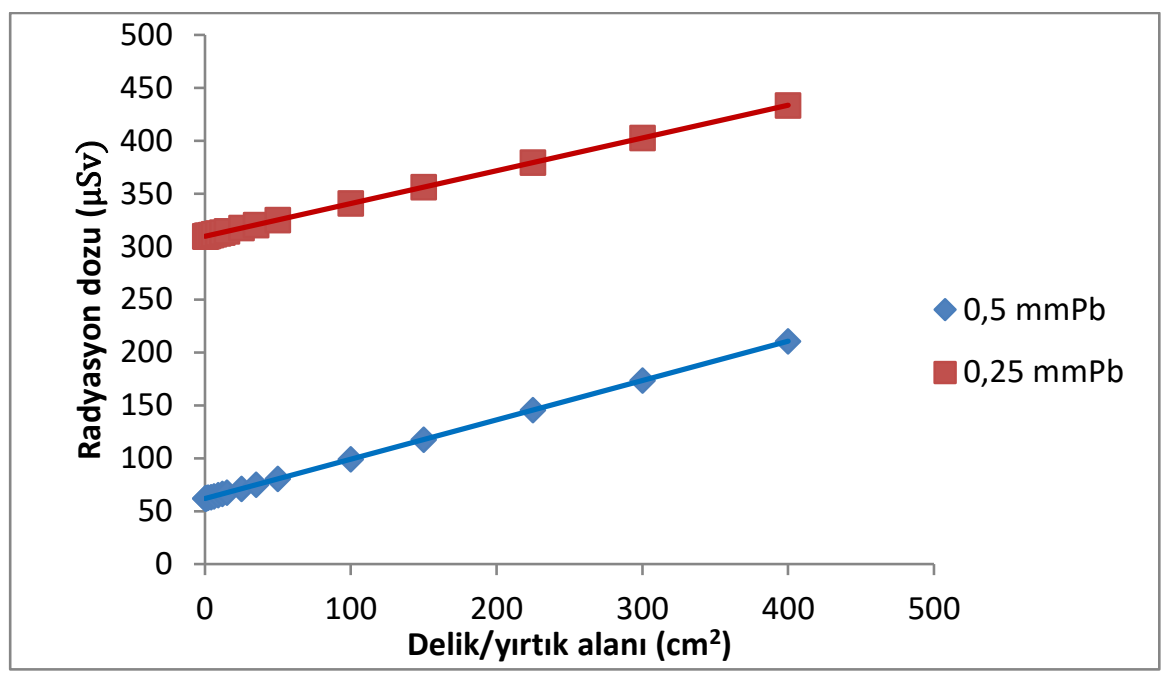

Şekil 6. 0,25 Pbmm ve 0,5 mmPb kurşun önlük için toplam etkin doz ĕgrisi

Şekil 6'daki eğriler referans alınarak önümüzdeki yıllarda yapılacak olan kurşun koruyucu giysilerin kalite kontrol çalışmalarında belirlenen delik/yırtık alanı ve tanımlanan doz kriterlerine göre hasarlı koruyucuları kolaylıkla değerlendirmek mümkün olacaktır.

Radyasyon uygulamalarında çalışanlar, radyasyondan korunmak için kurşun ya da kompozit malzemeden oluşan koruyucu giysiyi sıklıkla kullanırlar ve bu giysiler kullanım koşullarına göre zamanla hasar görebilmektedir. Bu nedenle söz konusu koruyucu giysilerin yılda bir kez kalite kontrol çalışmalarının yapılması gerekmektedir. Bu çalışmaların sonucunda, atık nedenini belirlemedeki en büyük problem; “tespit edilen yırtık alanı ne kadar olmalı?", "yırtık sayısı kaç tane olmalı?” veya "bu yırtıktan ne kadar radyasyon geçer/geçmeli?" ve "hasarlı koruyucular için atık kriterim ne olmalı?" sorularının cevabıdır. Bu nedenle, öncelikle maliyeti oldukça yüksek olan kurşun önlüklerin (400\$-1.200\$) kalite kontrol çalışması sonucunda, riskli ve hasarlı olarak belirlenmesi gerekmektedir. Atık demek için kriterlerin ne olması gerektiğini belirlemek zordur, ancak kişinin bireysel değerlendirilmesine de bırakılmamalıdır. Bu konunun önemini vurgulayarak ilk atık kriterlerini tanımlayan, Lambert ve McKeon olmuştur. Onlar, basit bir oran ile ortalama kurşun koruyucu giysi maliyetinin $400 \$$ olmasını göz önüne alarak, kurşun önlüğün hasarından dolayı doz kriteri, 0,4 mSv olarak belirlemiştir. $0,4 \mathrm{mSv}$ değeri baz alındığında, eğer bir kurşun önlüğün toplam hasar alanı $670 \mathrm{~mm}^{2}(29 \mathrm{~mm}$ çaplı bir delik) ise bu önlük atılmalı ve yenisi alınması gerektiği vurgulanmıştır (Lambert ve McKeon, 2001). Stam ve Pillay, yaptıkları çalışmada; atık kriteri oluşturmak için yasal yıllık doz limiti 20 mSv'lık dozun \%10'u, yani 2 mSv/yıl en düşük doz olarak göz önüne almışlardır (Stam ve Pilay, 2008). Kurşun önlükteki büyük bir delikten dolayı ek etkin doz değeri, yıllık dozu 3 'te bir oranında etkileyeceği ve bunun yanısıra ampirik olarak $1 / 3$ faktörüyle dozda azalma gerçekleşmesi pratik atık kriterini oluşturduğunu ifade etmişlerdir. (ICRP Pun.35, 1982b). Bu nedenle ek doza bağlı atık kriteri, ( $\left.E_{\text {ek-attk }}=1 / 3 \times 1 / 3 \times 2 \mathrm{mSv}\right) 0,22 \mathrm{mSv}$ olarak belirlemişlerdir. Yaptıkları çalışmada, 96 önlükten \%3'lük kısmının 0,62 $\mathrm{mSv}$ ve $0,79 \mathrm{mSv}$ lık gibi kabul edilemeyen ek dozlarından dolayı atık olarak belirlemişlerdir (Stam ve Pilay, 2008). Duran ve Philips ise yaptıkları çalışmada, tüm vücut kurşun önlükte $10 \mathrm{~cm}^{2}$, böyle bir önlüğün troid kısmında ise $0,2 \mathrm{~cm}^{2}\left(20 \mathrm{~mm}^{2}\right)$ bir yırtık, atık kriterini oluşturmuştur. Ayrıca kullanılan troid koruyucular için atık kriteri ise $0,03 \mathrm{~cm}^{2}\left(3 \mathrm{~mm}^{2}\right)$ iken zırhlı bir eldiven için bu değer $3 \mathrm{~cm}^{2}$ olarak bulunmuştur. Bununla birlikte \% geçirme oranları için sağlam alandaki geçirme miktarının \%5 fazlası atık kriteri olarak alınmıştır (Duran ve Emmy, 2003).

$\mathrm{Bu}$ çalı̧̧malar 1şığında çalışmamızda atık kriterleri, delik/yırtık alanının $10 \mathrm{~cm}^{2}$ ve fazlası, \% geçirme oranları $\% 5$ ve fazlası ve etkin doz değeri $0,4 \mathrm{mSv}$ olarak belirlendi. Çalışmamızda, gonad ve troid koruyucularda herhangi bir hasar bulunmamakla birlikte kurşun önlük değerlendirmesinde sadece tek kat kurşun önlük tipi değerlendirmeye alındı. Bu koşullar altında gerçekleştirilen çalışmaya göre bir ya da birden fazla delik/yırtık olan kurşun önlüklerin \% $\%, 8$ 'i hasarlı olarak belirlenirken \%12,8'i riskli olarak değerlendirildi.

$\mathrm{Bu}$ çalışma sonucunda; kurşun önlüklerin hasarlı olanlarının atılarak yerine yenilerinin alınmasına ve riskli olarak belirlenenlerin 6 ay sonra tekrar değerlendirilmesine karar verildi. Bununla birlikte çalışmanın sonunda elde ettiğimiz delik/yırtık alanına karşı çizilen etkin doz kalibrasyon eğrisi, sonraki yıllarda kurşun önlük kalite kontrol çalışmalarında delik/yırtık alanı göre etkin doz değerlerinin bulunmasında kolaylık sağlayacaktır. Böylelikle daha pratik bir şekilde hasarlı ve atık önlüklerin tespiti yapılabilecektir. Bununla birlikte, $0,5 \mathrm{mmPb}$ önlüklerin daha iyi koruma sağlaması amacıyla tercih edildiği görülmüştür. Ağır olması nedeniyle taşıması zor ve hasarlanma olasılığı yüksek olan bu $0,5 \mathrm{mmPb}$ kurşun önlükler yerine çalışma alanına uygun $0,35 \mathrm{mmPb}$ veya eşdeğeri kompozit malzemeden yapılmış koruyucuların kullanılması önerilir. 


\section{Sonuç}

$\mathrm{Bu}$ çalışma sonucunda, hasarlı kurşun önlüklerin atık kriterlerine bağlı olarak kullanımdan çıkarılması, gereksiz kurşun önlük atı̆̆ının olmasını önlemiştir. Kurşun önlük incelemelerinin, yıllık kalite kontrol çalışmaları içinde düzenli yapılması atık oranlarını daha da düşürebileceği söylenebilir. Ayrıca bu çalışma radyasyon çalışanlarına kişisel korunmada koruyucu giysileri daha güvenle kullanabilecekleri güvenini sağlayacaktır. Bu çalışma sonucunda elde edilen atık kriterleri, hastaneler ve ilgili kurumlarda kullanılan kurşun koruyucu giysilerin kalite kontrolleri sonrasında atık kararının belirlenmesine yol gösterici olacaktır.

\section{Teşekkür}

Yazarlar, hastanemiz Radyasyon Güvenliği Komitesi ile işbirliği içerisinde gerçekleştirilen bu çalışmada floroskopi cihazının kullanımını izin veren Radyoloji AD’ına teşekkürü bir borç bilir.

\section{Kaynakça}

Çetin H, Yurt A, Yüksel SH. The absorption properties of lead-free garments for use in radiation protection. Radiat Prot Dosim 2016; 73(4):345-350.

Duran P and Emmy B. Rejection criteria for defects in lead apparel used for radiation protection of $\mathrm{x}$ ray workers. Radiation Protection Services BC Centre for Disease Control 2003; p:1-7.

International Commission on Radiological Protection. General principles of monitoring for radiation protection of workers. Oxford Pergamon Press; ICRP Publication 35. Ann ICRP 9(4):1982b.

International Commission on Radiological Protection. Protection from ionizing radiation from external sources used in medicine. Oxford: Pergamon Press; ICRP Publication 33, Ann ICRP 9(1);1982a.

Jones A and Wagner L. On the (f)utility of measuring the lead equivalence of protective garments. Med Phys 2013; 40(6): 063902-1063902-9.

Lambert K. and McKeon T. Inspection of lead aprons: criteria for rejection. Health Phys 2001; 80(5): 67-9.

Oyar O. and Kışlalığlu A. How protective are the lead aprons we use against ionizing radiation? Diagn Interv Radiol 2012; 18: 147152.

Stam W. and Pilay M. Inspection of lead aprons: A practical rejection model. Operational Rad Safety 2008; 95(2): 133-136.

Zuguchi M, Chida K, Taura M, Inaba Y, Ebata A, Yamada S. Usefulness of non-lead aprons in radiation protection for physicians performing interventional procedures. Radiat Prot Dosim 2008; 131(4):531-534. 